\title{
Sustentabilidade em sistemas produtivos no município de Serraria, Paraíba
}

\section{Productive systems Sustainable in the Serraria County, Paraiba, Brazil}

\author{
Juliana Ferreira de Limal, Jair Batista de Souza ${ }^{1}$, Alex da Silva Barbosa ${ }^{2}$
}

${ }^{1}$ Programa de Pós-Graduação em Ciências Agrárias (Agroecologia), Universidade Federal da Paraíba, Campus de Bananeiras, julianacavnufpb@ hotmail.com, jair.tec.agropecuaria@gmail.com; ${ }^{2}$ Professor do Departamento de Agricultura. Universidade Federal da Paraíba, Campus de Bananeiras, aldasibarbosa@gmail.com

\author{
N O T A \\ C I E N T Í F I C A
}

Recebido: $20 / 08 / 2019$

Aprovado: 09/12/2019

\section{Palavras-chave:}

Agricultura familiar

Agroecologia

Sistemas Agroflorestais

\section{R E S U M O}

A adoção de práticas agroecológicas como consórcio e sistemas agroflorestais mostram-se eficazes na melhoria e manutenção da qualidade dos solos, sendo imprescindível a delimitação de fatores que possam estar relacionados a preservação da fertilidade dos solos. Os indicadores de sustentabilidade de solos participativos caracterizam-se pela sua facilidade na aplicação, podendo serem utilizados pelos próprios agricultores e contribuindo com melhorias nos sistemas de produção da agricultura familiar. Objetivou-se quantificar os níveis de resiliência e diversidade nos diferentes agroecossistemas localizados no município de Serraria, Paraíba. Os agroecossistemas estudados possuíam três consórcios, três monocultivos e três áreas em transição para um sistema agroflorestal. Para o estudo foi utilizado o Diagnóstico Rural Participativo como ferramenta combinada com o método de atribuição de notas aplicados para os indicadores sociais, econômicos e sustentáveis. Em todos os sistemas não são utilizados fertilizantes químicos solúveis industrializados e agrotóxicos em seu manejo, sendo o modelo de produção familiar. A partir das análises pode-se concluir que em áreas pequenas de monocultivo é possível garantir um certo nível de resiliência do agroecossistema, quando trabalhado de maneira em atinência aos princípios do manejo e conservação.

A B S T R A C T
The adoption of agroecological practices such as consortium and agroforestry systems are
effective in improving and maintaining soil quality, with the delimitation of factors that
may be related to the preservation of soil fertility being essential. The indicators of
sustainability of participative soils are characterized by their ease of application, which can
be used by farmers themselves and contributing to improvements in family farming
production systems. The objective was to quantify the levels of resilience and diversity in
the different agroecosystems located in the Serraria, PB County. The studied
agroecosystems had three contortium, three monocultures and three areas in transition to an
agroforestry system. For the study, the Participative Rural Diagnosis was used as a tool
combined with the method of attributing scores applied to social, economic and sustainable
indicators. In not all systems, soluble chemical fertilizers and pesticides are used in their
management, being the model of family production. From the analysis, it can be concluded
that in small monoculture areas it is possible to guarantee a certain level of resilience of the
agroecosystem when worked in a manner in keeping with the principles of management
and conservation.

Key words:

Family farming

Agroecology

Agroforestry Systems

\section{INTRODUÇÃO}

A agroecologia não se restringe ao manejo dos recursos naturais em bases ecológicas, mas se constitui também de uma importante estratégia para a análise dos impactos socioambientais e para a implementação de programas de desenvolvimento rural em bases sustentáveis (MOREIRA;
CARMO, 2004). A sustentabilidade, por sua vez, é definida por Nicholls et al. (2004), como um conjunto de requisitos agroecológicos que devem ser satisfeitos por qualquer unidade de produção independente do modelo de gestão, do nível econômico e do nível tecnológico. Entretanto, o processo de construção de uma agricultura sustentável deve passar, necessariamente, pelo fortalecimento da agricultura de base

\section{Revista Verde}

ISSN 1981-8203

Pombal, Paraíba, Brasil v. 15 , n.1, jan.-mar, p.105-110, 2020
doi: $10.18378 /$ rvads.v15i1.6881 
familiar, por profundas modificações na estrutura fundiária do País e por políticas públicas consistentes e coerentes com a emancipação de milhões de agricultores brasileiros (MOREIRA; CARMO, 2004).

Assim sendo a produção em sistemas sustentáveis mostra-se promissora, pois promove a ciclagem de nutrientes não necessitando de insumos externos. Esse sistema de produção também é capaz de melhorar as características físicas químicas e biológicas do solo (VIEIRA et al., 2015). Nesse sentido, para monitorar o sistema de produção, os estudos sobre os indicadores de sustentabilidade são fundamentais para que se estabeleça, com base na qualidade do solo e acumulo de fitomassa, os subsídios necessários ao planejamento dos sistemas de produção agroecológicos (SIMÕES et al., 2018).

$\mathrm{Na}$ análise de agroecossistemas no que diz respeito ao solo pode-se citar a densidade do solo o teor de carbono orgânico, o índice de estabilidade estrutural, a condutividade hidráulica saturada, a macroporosidade, a capacidade de aeração, a capacidade de água disponível para a planta e a capacidade de campo relativa como os principais indicadores de qualidade do solo (REYNOLDS et al., 2009). Todavia, existem outros indicadores que podem ser mensurados pelo próprio agricultor, sem o uso de equipamentos sofisticados, facilitando a classificação e acompanhamento do sistema. Nesse sentido, deve-se priorizar os indicadores que sejam sensíveis as alterações de manejo, pois esses são capazes de revelar as vantagens e desvantagens dos diferentes modelos de usos da terra (SIMÕES et al., 2018).

A adoção de manejos mais sustentáveis, tais como, consórcio, adubação orgânica e sistemas agroflorestais, são estratégias que podem contribuir para a melhoria das qualidades físicas, químicas e biológicas dos solos sendo, portanto, práticas que podem garantir a produção a longo prazo em condições mais equilibradas e dinâmicas com o meio em que estão inseridas.

Para trabalhar com a sustentabilidade de agroecossistemas, é necessário conhecer o ambiente no qual estar inserido, bem como os recursos disponíveis, a mão de obra e as vocações de cada região. Neste trabalho, abordou-se a realidade de alguns agroecossistemas familiares do município de Serraria-PB, os quais vêm passando por um processo de transição agroecológica, ou onde os agricultores têm o interesse de iniciar essa transição.

De acordo com Lima (2019), no município de Serraria$\mathrm{PB}$, a agricultura familiar predomina em áreas pequenas, que normalmente variam de 0,5- 5,0 ha, onde são produzidos alimentos de maneira diversificada para subsistência familiar, e, o excedente é comercializado nas feiras livres, em feiras da agricultura familiar, para atravessadores, de porta em porta (na cidade), ou mesmo na propriedade. Também há a comercialização em feiras livres das cidades vizinhas, destacando-se o milho, feijão, macaxeira, mandioca, fava, banana, urucum, caju e inhame.

Assim, objetivou-se quantificar os níveis de resiliência e diversidade nos diferentes agroecossistemas localizados no município de Serraria, Paraíba.

\section{MATERIAL E MÉTODOS}

A sistematização foi realizada no período de 20 de abril a 30 de maio de 2017, em diferentes unidades produtivas no município de Serraria, Brejo paraibano. Serraria é um município paraibano, localizado na mesorregião do agreste e microrregião do brejo, no Território da Borborema, conforme classificação do Ministério do Desenvolvimento Agrário (MDA), com uma área de $65.299 \mathrm{~km}^{2}$, com uma população estimada em 2018 de 6.131 habitantes (BRASIL, 2018).

Como objeto de pesquisa deste trabalho, foram analisados os seguintes agroecossistemas: três em transição para Sistemas Agroflorestais (SAFs), sendo estes um quintal agroflorestal, um SAF de coco e laranjeiras com inhame e batata doce, e um SAF com pitombeiras, jabuticabeiras, mangueiras e outras frutíferas; três consórcios de culturas de subsistência (feijão, milho, mandioca e fava); três monocultivos sem a utilização fertilizantes químicos solúveis industrializados e agrotóxicos, sendo respectivamente um bananal de aproximadamente 1,0 ha, área de produção de urucum de aproximadamente 2,0 ha, e área de produção de inhame de 1,0 ha.

A metodologia adotada foi a participativa com o Diagnóstico Rural Participativo (DRP) como uma ferramenta metodológica a partir da qual foi possível analisar questões ambientais, sociais, econômicas, políticas e culturais de comunidades rurais, visando o desenvolvimento local, através de um processo de intercâmbio de aprendizagem entre os agentes externos (técnicos) e os membros da comunidade na qual se realiza (PAREYN et al., 2006).

Foi realizado um reconhecimento prévio das respectivas propriedades através de uma caminhada transversal com os proprietários, além da caminhada transversal e da aplicação das entrevistas, também realizou-se um diálogo participativo, onde os agricultores (as) entrevistados puderam abordar um pouco da história de cada propriedade, de quando às adquiriram, como era a vegetação anterior do local, se reflorestaram ou não, quais as principais culturas e também criações animais da propriedade.

Alguns indicadores foram avaliados a partir de observações diretas no momento da caminhada transversal com os agricultores, tais como diversidade vegetal da propriedade, presença de plantas nativas, dentre outros. Foram aplicados os indicadores de acordo com a metodologia de Nicholls et al., (2004), onde para cada resposta do agricultor atribuiu um valor de 1, 5 e 10. Cada agricultor foi entrevistado por 2 avaliadores que atribuíram os referidos valores e posteriormente, submetido aos cálculos de índice de sustentabilidade.

De posse dos dados coletados realizou-se a tabulação no software Excel (Microsoft Office, 2010). Os indicadores de sustentabilidade utilizados para avaliação dos parâmetros socioeconômicos e ambientais dos agroecossistemas foram feitos de acordo com a metodologia de Nicholls et al. (2004), com adaptações conforme tabelas 01,02 e 03.

Tabela 01. Indicadores de sustentabilidade na dimensão econômica.

\begin{tabular}{ll}
\hline \multicolumn{1}{c}{ Indicadores } & Características \\
\hline $\begin{array}{l}\text { Produtividade e } \\
\text { rentabilidade }\end{array}$ & $\begin{array}{l}\text { 1.Baixa } \\
\text { 5.Média } \\
\text { 10.Alta }\end{array}$ \\
\hline \multirow{2}{*}{$\begin{array}{l}\text { Participação em } \\
\text { programas }\end{array}$} & $\begin{array}{l}\text { programa participa de feiras nem de } \\
\text { governamentais } \\
\text { e/ou feiras }\end{array}$ \\
& $\begin{array}{l}\text { do governo } \\
\text { 10.Participa de feiras e de programa } \\
\text { do governo }\end{array}$ \\
\hline & 1.Monocultivo sem criação de animais
\end{tabular}

Revista Verde, v.15, n.1, p.105-110, 2020 


\begin{tabular}{|c|c|}
\hline $\begin{array}{l}\text { Diversificação } \\
\text { do sistema } \\
\text { produtivo }\end{array}$ & 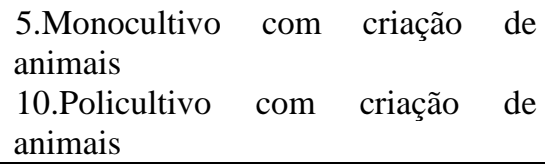 \\
\hline Mão de obra & $\begin{array}{l}\text { 1.Trabalha sozinho } \\
\text { 5.Trabalha e contrata mão de obra } \\
\text { 10.Mão de obra familiar }\end{array}$ \\
\hline Comercialização & $\begin{array}{l}\text { 1.Produz apenas para o consumo } \\
\text { 5.Vende para o atravessador } \\
\text { 10.Vende diretamente ao consumidor }\end{array}$ \\
\hline $\begin{array}{l}\text { Agregação de } \\
\text { valor }\end{array}$ & $\begin{array}{l}\text { 1.Vende sem nenhum beneficiamento } \\
5 . \text { Vende com algum tipo de } \\
\text { embalagem } \\
\text { 10.Beneficia e agrega valor }\end{array}$ \\
\hline $\begin{array}{l}\text { Gastos com } \\
\text { fertilizantes, } \\
\text { agrotóxicos, etc. }\end{array}$ & $\begin{array}{l}\text { 1.Toda produção é feita com } \\
\text { agrotóxicos } \\
\text { 5.Utiliza agrotóxicos e defensivos } \\
\text { naturais } \\
\text { 10.Não utiliza agrotóxicos }\end{array}$ \\
\hline Crédito rural & $\begin{array}{l}\text { 1.Nunca fez uso } \\
\text { 5.Obtém com dificuldade } \\
\text { 10.Sempre obtém }\end{array}$ \\
\hline $\begin{array}{l}\text { Implementos } \\
\text { agrícolas }\end{array}$ & $\begin{array}{l}\text { 1.Sucateados } \\
\text { 5.Em bom estado de conservação } \\
\text { 10.Novos }\end{array}$ \\
\hline $\begin{array}{l}\text { Produção ao } \\
\text { longo do ano }\end{array}$ & $\begin{array}{l}\text { 1.Até } 4 \text { meses } \\
\text { 5.De } 4 \text { a } 8 \text { meses } \\
\text { 10.Durante todo ano }\end{array}$ \\
\hline
\end{tabular}

Tabela 02. Indicadores de sustentabilidades na dimensão social.

\begin{tabular}{|c|c|}
\hline Indicadores & Características \\
\hline $\begin{array}{c}\text { Saúde e } \\
\text { saneamento }\end{array}$ & $\begin{array}{l}\text { 1.Não possui banheiro } \\
\text { 5. Possui banheiro } \\
\text { 10. Possui banheiro e agente de saúde }\end{array}$ \\
\hline $\begin{array}{l}\text { Aspectos } \\
\text { culturais }\end{array}$ & $\begin{array}{l}\text { 1.Não participa de atividades culturais } \\
\begin{array}{l}\text { 5.Às vezes participa de atividades } \\
\text { culturais }\end{array} \\
\begin{array}{l}10 \text {. Sempre participa de atividades } \\
\text { culturais }\end{array}\end{array}$ \\
\hline Form & $\begin{array}{l}\text { 1.Não estudou } \\
\text { 5. Ensino fundamental } \\
\text { 10.Ensino médio, técnico ou superior }\end{array}$ \\
\hline Lazer & $\begin{array}{l}\text { 1.Não dedica tempo ao lazer } \\
\text { 5.Faz atividade de lazer raramente } \\
\text { 10.Sempre que possível }\end{array}$ \\
\hline $\begin{array}{c}\text { Participação } \\
\text { social }\end{array}$ & $\begin{array}{l}\text { 1.Não participa de atividades da } \\
\text { comunidade } \\
\text { 5.Participa de sindicato, associação e da } \\
\text { igreja (pouco) } \\
\text { 10.Participa de sindicato, associação e da } \\
\text { igreja, etc. (muito) }\end{array}$ \\
\hline $\begin{array}{c}\text { Relações com } \\
\text { a agricultura }\end{array}$ & $\begin{array}{l}\text { 1.Atividade secundária } \\
\text { 5.Atividade principal } \\
\text { 10.Atividade principal }+ \text { artesanato }\end{array}$ \\
\hline $\begin{array}{l}\text { Atividades de } \\
\text { construção de } \\
\text { conhecimentos }\end{array}$ & $\begin{array}{l}\text { 1.Não participa } \\
\text { 5.Participa pouco } \\
\text { 10.Sempre participa }\end{array}$ \\
\hline $\begin{array}{l}\text { Participação } \\
\text { das mulheres }\end{array}$ & $\begin{array}{l}\text { 1.Não participam } \\
\text { 5.Participam pouco } \\
\text { 10.Sempre participam }\end{array}$ \\
\hline
\end{tabular}

1.Não tem assessoria técnica

5.Recebe assessoria tec. da EMATER

Assessoria

10.Recebe orientações técnicas

(EMATER, sindicato, UFPB, dentre outros).

\section{Arrendada}

Posse da terra 5.Assentamento da Reforma Agrária 10.Própria

Adaptado de Nicholls et al. (2004)

Tabela 03. Indicadores de sustentabilidade na dimensão ambiental.

\begin{tabular}{|c|c|}
\hline Indicadores & Características \\
\hline $\begin{array}{c}\text { Aparência do } \\
\text { solo }\end{array}$ & $\begin{array}{l}\text { 1.Solo "nu" (sem Matéria orgânica) } \\
\text { 2.Solo com pouca MO } \\
\text { 10.Solo com bastante MO }\end{array}$ \\
\hline $\begin{array}{c}\text { Diversidade } \\
\text { vegetal }\end{array}$ & $\begin{array}{l}\text { 1.Monocultura sem árvores } \\
\text { (sombreamento) } \\
\text { 5.Monocultura com poucas árvores } \\
\text { 10.Policultivo com sombreamento }\end{array}$ \\
\hline $\begin{array}{c}\text { Diversidade } \\
\text { genética }\end{array}$ & $\begin{array}{l}\text { 1.Uma só variedade dominante. } \\
\text { 5.Duas variedades dominantes. } \\
\text { 10.Mais de duas variedades dominantes. }\end{array}$ \\
\hline $\begin{array}{l}\text { Sistema de } \\
\text { manejo }\end{array}$ & $\begin{array}{l}\text { 1.Monocultura convencional com } \\
\text { agrotóxicos } \\
\text { 5.Em transição para produção orgânica } \\
\text { 10.Produção orgânica }\end{array}$ \\
\hline $\begin{array}{c}\text { Adequação } \\
\text { ambiental }\end{array}$ & $\begin{array}{l}\text { 1.Não possui cisternas nem plantas ou } \\
\text { animais adaptados a região } \\
\text { 5.Possui cisterna } \\
\text { 10.Possui cisternas, plantas e animais } \\
\text { adaptados }\end{array}$ \\
\hline $\begin{array}{l}\text { Profundidade } \\
\text { do solo }\end{array}$ & $\begin{array}{l}\text { 1.Subsolo exposto } \\
\text { 5.Solo superficial fino (menos de } 10 \mathrm{~cm}) \\
\text { 10.Solo superficial mais profundo }(+\mathrm{de} 10 \\
\mathrm{cm})\end{array}$ \\
\hline $\begin{array}{c}\text { Processos } \\
\text { erosivos }\end{array}$ & $\begin{array}{l}\text { 1.Erosão severa } \\
\text { 5.Erosão evidente (pouca) } \\
\text { 10.Sem sinais de erosão }\end{array}$ \\
\hline $\begin{array}{l}\text { Atividade } \\
\text { biológica no } \\
\text { solo }\end{array}$ & $\begin{array}{l}\text { 1.Sem sinais de atividade biológica } \\
\text { 5.Presença de alguns invertebrados e } \\
\text { insetos } \\
\text { 10.Presença de muita atividade biológica }\end{array}$ \\
\hline $\begin{array}{l}\text { Origem das } \\
\text { sementes }\end{array}$ & $\begin{array}{l}\text { 1.Compra em feiras/mercados e recebe de } \\
\text { órgãos governamentais } \\
\text { 5.Armazena um pouco e compra ou recebe } \\
\text { de órgãos governamentais } \\
\text { 10.Armazena para a safra seguinte }\end{array}$ \\
\hline $\begin{array}{l}\text { Diversidade } \\
\text { natural } \\
\text { circundante }\end{array}$ & $\begin{array}{l}\text { 1.Rodeado por outros cultivos, sem } \\
\text { vegetação natural } \\
\text { 5.Uma das laterais predomina a vegetação } \\
\text { natural } \\
10.50 \% \text { da vegetação circundante é natural }\end{array}$ \\
\hline
\end{tabular}
Adaptado de Nicholls et al. (2004)

\section{RESULTADOS E DISCUSSÃO}

De maneira geral, os agroecossistemas avaliados têm como caraterística comum o não uso de fertilizantes químicos solúveis industrializados em seu manejo produtivo, possuem uma boa diversidade vegetal, mesmo naqueles agroecossistemas que apresentam áreas de monocultivos. 
Essas características contribuíram para que os resultados obtidos fossem semelhantes em alguns parâmetros, se aproximando, portanto, das diretrizes praticadas na Agroecologia, que para Costa (2016), é uma alternativa viável para reverter o atual quadro de devastação socioambiental provocado pela agricultura convencional. Contudo, salienta-se que o não uso de fertilizantes químicos industrializados não garante que a propriedade esteja de acordo com os princípios e práticas agroecológicas para isso seria necessário o atendimento de outros indicadores como a diversidade produtiva, a participação familiar na produção, dentre outras estratégias.

Na dimensão econômica, podemos observar que em nenhum dos ecossistemas há o uso de agrotóxicos, conforme figura 01, o que contribui para sustentabilidade ambiental e econômica dos agroecossistemas e se contrapõe com o manejo praticado na agricultura convencional brasileira sendo uma das que mais utilizada agrotóxicos no mundo (COSTA, 2016).

Figura 1. Níveis de resiliência na dimensão econômica dos agroecossistemas no município de Serraria, Paraíba.

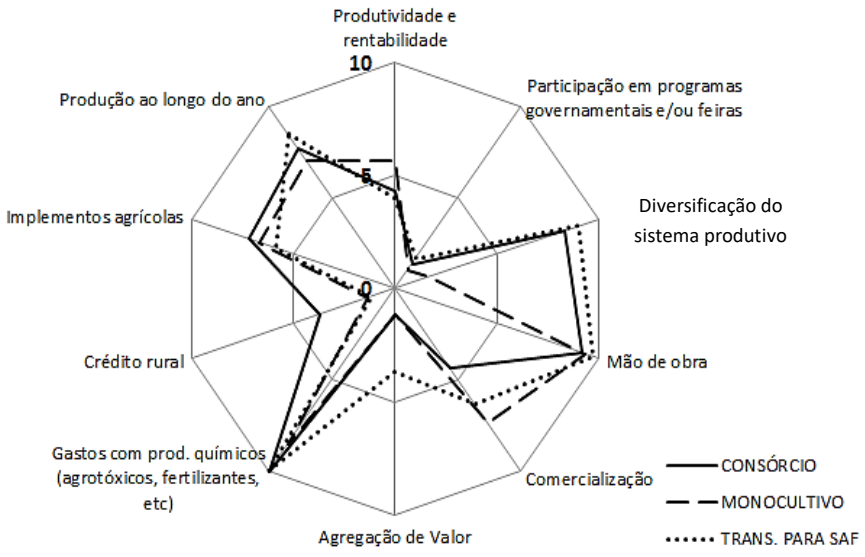

O não uso de agrotóxicos contribui também com o bemestar dos produtores e de suas famílias uma vez que para Melo e Araújo (2016), o uso de produtos químicos pode provocar problemas de saúde nos agricultores e animais além de poluir o meio ambiente. Outro fator que contribui para a sustentabilidade econômica do agroecossistema é a mão de obra caracterizada por ser de origem familiar, o que além de reduzir os gastos com as atividades produtivas, fortalece os vínculos familiares e possibilita a apropriação dos jovens (quando envolvidos nas atividades produtivas) pela profissão dos pais e valorização da agricultura familiar.

O sistema de monocultivo apresenta menor diversificação de sua forma de produção, entretanto por ser praticado em pequenas áreas, sem o uso de fertilizantes químicos industrializados e preservação de algumas árvores nativas nas proximidades das áreas de produção não causou grande impacto em alguns indicadores de sustentabilidade avaliados.

Como podemos observar na figura 01, quanto à produtividade e a rentabilidade, os agroecossistemas com SAF em processo de transição se destacam. Esse melhor índice se dá devido à diversificação da produção ao longo do ano, assegurando que ao fim da safra de determinado produto outra já se inicie, como por exemplo as safras das frutíferas, permitindo a resiliência e autonomia da propriedade.

Segundo Oliveira et al. (2013), o modelo agroecológico mesmo quando em transição pode ser uma estratégia para o desenvolvimento rural e justiça social em nosso país. Os SAF’s são uma importante estratégia para a transição agroecológica uma vez que neles a necessidade de insumos é menor quando comparado aos monocultivos, pois a maior biodiversidade gera mais interações ecológicas entre os componentes do sistema (LIMA et al. 2013).

Nos SAF's também podemos identificar um maior equilíbrio econômico. O equilíbrio econômico advém da não necessidade de compra de insumos, que são bastante caros. Nesse sistema uma planta ajuda outra a adquirir macro e micronutrientes necessários, procurando imitar a natureza propiciando uma independência de produtos industrializados e uma maior autonomia dos agricultores em relação aos insumos. Nos sistemas de monocultivos há uma forte presença do atravessador, os agricultores justificam a presença do intermediário em virtude das dificuldades para comercializar toda a produção de forma independentemente.

$\mathrm{Na}$ figura 02 observa-se que os monocultivos encontramse em áreas que o agricultor não tem a posse da terra, já os SAF's em transição e mesmo os consórcios localizam-se em áreas onde os agricultores são proprietários. A propriedade da terra é muito importante para a autonomia dos agricultores já que sem sua posse irão sempre depender de outras pessoas para conseguirem trabalhar e retirar da terra o seu próprio sustento.

Figura 2. Níveis de resiliência na dimensão social dos agroecossistemas no município de Serraria, Paraíba.

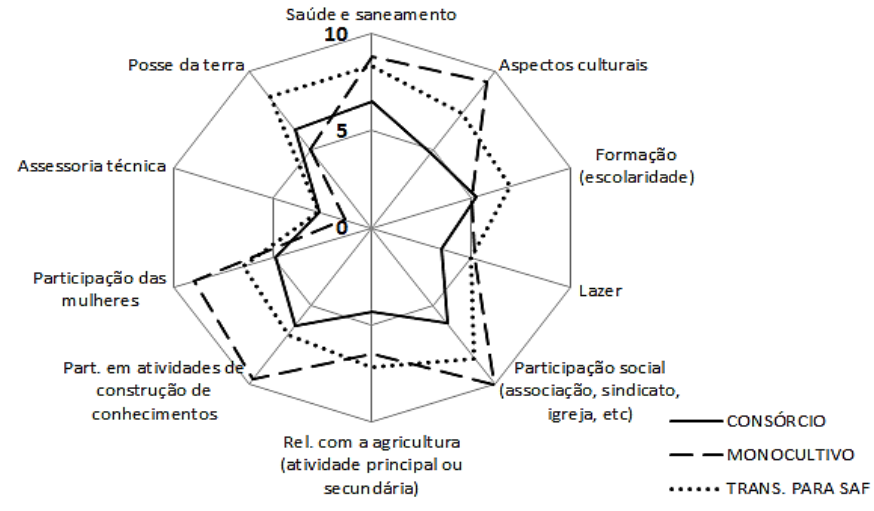

Em todas as áreas foi detectado um índice de falta de assessoramento técnico continuado para a produção. $\mathrm{O}$ que corrobora com Noce e Ferreira Neto (2016), ao afirmarem que faltam políticas públicas voltadas para a agricultura familiar. Essa falta de assistência técnica impede que os agricultores tenham acesso a novas tecnologias que poderiam incrementar a produção sem necessariamente causar danos ao meio ambiente. Os agricultores asseguram que as experiências desenvolvidas na produção foram passadas de pais para filhos e em cursos e oficinas que participaram ao longo da vida, assim como a maioria das sementes utilizadas nas propriedades são oriundas da própria localidade.

Em todas as propriedades as mulheres participam ativamente das atividades desenvolvidas na propriedade, bem como em atividades externas de construção e socialização de conhecimentos. Essa participação é de extrema importância. Essa atitude contribui com o seu empoderamento e confirma seu importante papel para a persistência da família na localidade (REFATI et al. (2017). A participação social em oficinas, reunião de associação, palestras, dentre outras, também é bem difundida em todos os sistemas, o que fortalece os vínculos entre a comunidade e a percepção de novas experiências produtivas a serem implementadas pela família. 
No tocante aos índices de sustentabilidade na dimensão ambiental, nos sistemas em transição para SAF's, verificou-se uma maior diversidade genética, vegetal e com melhores valores de aparência dos solos. Quanto à atividade biológica visível a olho nu, os valores foram inferiores aos outros sistemas de produção.

Nos consórcios, alguns indicadores foram diferentes aos do SAF's apresentando variações principalmente nos aspectos de diversidade genética e vegetal, sistema de manejo e profundidade do solo. Quando comparado aos monocultivos, os consórcios apresentaram melhores índices também de diversidade genética, vegetal e profundidade do solo, além de sistema de manejo, consolidando com Valani et al. (2016), onde relatam melhores características de solo nos consórcios quando comparado aos monocultivos.

Os sistemas de monocultivos apresentam baixa diversidade genética e vegetal, predominando apenas uma espécie por área (Figura 03). Os monocultivos obtiveram índices de sustentabilidade próximos aos do consórcio, isso provavelmente porque os cultivos são em pequena escala o que não provocam grandes diferenças entre esses agroecossistemas.

Figura 3. Níveis de resiliência na dimensão ambiental dos agroecossistemas no município de Serraria, Paraíba.

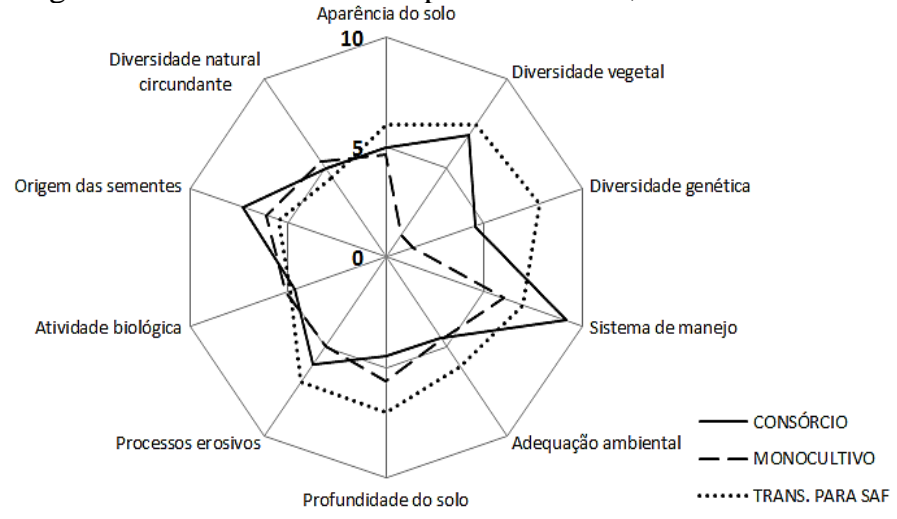

Outros fatores que conservaram a estrutura e aparência do solo para as áreas de SAF's e consórcios foram a não utilização de produtos químicos e a permanência das plantas rasteiras garantem a cobertura dos solos nesses agroecossistemas. Assim como, a permanência de árvores nativas nas áreas de produção e a presença da diversidade natural circundante em está presente em todas as áreas.

\section{CONCLUSÕES}

Os agroecossistemas de transição para sistema agroflorestal proporcionam melhor condição de ocupação da terra, diversidade e produção de culturas anuais e frutíferas, ao longo do ano, otimização de utilização da mão de obra e reduzem seus custos iniciais de implantação.

\section{REFERÊNCIAS}

BRASIL. Instituto Brasileiro de Geografia e Estatística (Org.). Infográficos: dados gerais do município. 2018. Disponível em: 〈https://cidades.ibge.gov.br/brasil/pb/serraria/panorama〉. Acesso em 23 de agosto de 2018.
COSTA, M. B. B. Reflexões sobre o Ensino Superior em Agroecologia. Cadernos de Agroecologia -- Vol. 11, No. 1, 2016.

LIMA, J. F. de. Feira da Agricultura Familiar de Serraria-PB e as Tecnologias Agroecológicas para o Fortalecimento e Valorização dos Agricultores Familiares. 2019. 102 f. Dissertação (Mestrado) - Curso de Pós-graduação em Ciências Agrárias (agroecologia), Universidade Federal da Paraíba, João Pessoa, 2019.

LIMA, G. L.; AZEVEDO, P. H.; BARROS, F.F. C.; BÍLIO, R. S.; GARCIA, S. S. Implicações socioambientais dos sistemas agroflorestais em unidades produtivas na região do Vale do Guaporé mato-grossense. Revista Acadêmica: Ciências Agrárias Ambientais. Curitiba, v. 11, Supl. 2, p. S137-S149, 2013. 10.7213/academica.10.S02.AO16

MELO, L. F.; ARAÚJO, A. E. Agroecologia e nutrição no combate a produção e consumo de agrotóxicos e na promoção de hábitos alimentares mais saudáveis. Revista Lugares de Educação. Bananeiras, v. 6, n. 12, p.125-138, 2016.

MOREIRA, R. M.; CARMO, M. S. do. Agroecologia na construção do desenvolvimento rural sustentável. Agric. São Paulo, v. 51, n. 2, p. 37-56, 2004.

MICROSOFT OFFICE. Suíte de Aplicativos. Microsoft, Redmond, WA, EUA. 2010.

NOCE, M. A.; FERREIRA NETO, J. A. Uma análise de política pública brasileira de desenvolvimento rural, com foco no combate à pobreza no campo. Cadernos de Ciências Sociais da UFRPE, vol. I, n. 8, 2016.

NICHOLLS, C. I.; ALTIERI, M. A.; DEZANET, A.; LANA, M. A Rapid, Farmer-Friendly Agroecological Method to Estimate Soil Quality and Crop Health in Vineyard Systems. Science and Ecology. Biodynamics. Autumn, 2004.

OLIVEIRA, M. A. C. de; SAMBUICHI, R. H. R; SILVA, A. P. M. da. Experiências agroecológicas brasileiras: uma análise à luz do desenvolvimento Local. Rev. Bras. de Agroecologia, 2013.

PAREYN, F.; GOMES, D.; FERREIRA, J. P.; SEBASTIÃO, E.; SILVA, J. da. Diagnóstico Rural Participativo: PA Catolé - Serra Talhada/PE. Recife, 2006. Disponível em: <http://www.plantasdonordeste.org/assentamento/Produto_1/ DRP_Catole.pdf >. Acesso em 06 junho de 2018.

REFATI, D. C; FABRINI, J. E; MARSCHNER, W. R. O trabalho das mulheres nos assentamentos Antônio Companheiro Tavares em São Miguel do Iguaçu e Ander Rodolfo Henrique em Diamante do Oeste - Paraná. Revista NERA, Presidente Prudente, Ano 20, nº. 35, pp. 83-107, JanAbr., 2017.

REYNOLDS, W. D,; DRURY, C. F.; ZHANG, T. Land management effects on the near-surface physical quality of a clay loam soil. Soil and Tillage Research, v. 96, p. 316-330, 2007. 10.1016/j.still.2007.07.003 
REYNOLDS, W.D.; DRURY, C. F.; TAN, C. S.; FOX, C. A. Use of indicator sand pore volume-function characteristics to quantify soil physical quality. Geoderma, v. 152, n. 3-4, p. 252263, 2009. 10.1016/j.geoderma.2009.06.009

SIMÕES, V. J. L. P.; LEITE, M. L. V.; SOUZA, E. S.; LUCENA, L. R. R.; IZIDRO, J. L. P.S. Indicadores de sustentabilidade com base na qualidade do solo e acúmulo de fitomassa em pastagens degradadas. Agrarian Academy, Centro Cientifico Conhecer, v.5, n.9; p. 253, 2018. 10.18677/Agrarian_Academy_2018a26

VALANI, G. P.; OLIOSI, G.; GONTIJO, I.; PARTELLI, F. L. Atributos físicos do solo em áreas de seringueira e pastagem em monocultivo contrastado ao sistema silvipastoril. Revista Univap. v. 22, n. 40, Edição Especial 2016. $\underline{10.18066 / \text { revistaunivap.v22i40.833 }}$

VIEIRA, M. V. M.; GIUNTI O. D.; GRIS, C.; SILVA, F., A. V. Indicadores de sustentabilidade e influência de sistemas agroflorestal e convencional sobre a qualidade do solo e do café arábica em Piumhi-MG. Revista Verde, v. 10, n.2, p. 229 - 238, 2015. 10.18378/rvads.v10i2.3329 